\title{
Simulation of total dust emission from palm oil mills in Malaysia using biomass fuel composition and dust collector efficiency models.
}

\begin{abstract}
Palm oil mills are generally self-sufficient in terms of energy. However, burning of biomass fuel in a boiler has generated serious air pollution problem due to inappropriate boiler operation and inefficient dust collection system. This study aims to simulate the total dust emission from palm oil mills in Malaysia by modelling biomass fuel composition and dust collector efficiency. It has been found that before removal, the simulated average dust load after biomass boiler was $51.67 \pm 5.39 \mathrm{~g} / \mathrm{s}$ at a confidence level of $95 \%$, and total dust load was 389,961 tonnes/year. Simulation values of total dust emission at different percentages of dust collector efficiency at $60 \%, 70 \%, 80 \%, 90 \%$ and $95 \%$ were 155,984, 116,988, 77,992, 38,996 and 19,498 tonnes/year, respectively. The simulation has also shown that dust concentration at a boiler outlet was $4.5 \mathrm{~g} / \mathrm{Nm} 3$. From the study, dust removal efficiency should be above $91 \%$ to ensure the compliance of dust concentration at $0.4 \mathrm{~g} / \mathrm{Nm} 3$ as prescribed by the Environment Quality (Clean Air) Regulations of 1978. Whereas in 2009, Sabah state has processed the most quantities of fresh fruit bunches; it has posed a potential impact on the environment and public in terms of total dust emission. Besides stack sampling that is used to monitor dust emission status, simulation can be a more simple way and an alternative to estimate the emission.
\end{abstract}

Keyword: Boiler; Biomass; Dust collector efficiency; Palm oil mill. 